\title{
Trialing an online intervention to improve retirement planning goal setting and goal specificity
}

This article was published in the following Dove Medical Press journal: Clinical Interventions in Aging

\author{
Joanne Kaa Earl' \\ Bianca Burbury ${ }^{2}$ \\ 'Department of Psychology, Macquarie \\ University, Sydney, NSW 2109 , \\ Australia; ${ }^{2}$ School of Psychology, \\ The University of New South Wales, \\ Sydney, NSW 2052, Australia
}

Purpose: Time perspective (TP) is the term used to describe people's preferences to focus on the past, present, and the future. Previous research demonstrates a link between TP and retirement planning. The objective of this study was to evaluate a TP-based online training intervention to improve retirement planning emphasizing the accumulation of resources.

Patients and methods: Twenty-two ( $M=59.41$ years) working and fully retired participants were compared to a control group of 18 ( $M=56.67$ years) participants. The intervention included three separate modules delivered online at the rate of one per week over a 3-week testing session. Outcomes focused on retirement goals and goal specificity.

Results: When compared to the control group, subjects in the intervention improved the number of goals relating to the accumulation of health $(F(1,35)=10.15, P<0.01,95 \% \mathrm{CI}$ $[0.28,2.77])$ and emotional resources $(F(1,35)=5.16, P<0.05,95 \%$ CI $[-0.22,2.37])$. Goals relating to the accumulation of health resources also became more specific within the experimental group when compared to the control group and a significant interaction was recorded $(F(1,38)=15.78, P<0.01,95 \%$ CI $[0.33,1.74])$. Similar interactions between the control and experimental groups were reported for the accumulation of cognitive resources $(F(1,38)=13.15, P<0.01,95 \%$ CI $[0.28,1.96])$ and for emotional resources $(F(1,38)=7.39$, $P<0.01,95 \%$ CI $[0.00,1.50])$. Qualitative feedback included recommendations to improve engagement by using more activities, providing clearer navigation instructions and avoiding the use of animation.

Conclusion: Applying a TP-based framework to the design of an online training intervention helped improve the accumulation and specificity of emotional and health resources for retirement. The study contains a number of theoretical and practical recommendations informing the design of future retirement planning interventions.

Keywords: resource accumulation, planning behavior, retirement, time perspective, retirement resources inventory, time perspective

\section{Introduction}

According to a recent survey of retirement intentions by the Australian Bureau of Statistics, ${ }^{1}$ there were almost a million people without a plan to retire, yet planning for retirement is a key requirement for securing wealth, improving positive psychological outcomes, and adjusting to retirement. ${ }^{2}$ Equally important for retirement adjustment and satisfaction is ongoing planning during retirement. ${ }^{3}$ Most of the research literature emphasizes preretirement planning although rarely in life are plans "set and forget" and retirement is no exception. The postretirement phase can be more financially precarious than preretirement because failure cannot be compensated and losses cannot be replaced. Planning ahead prior to workplace exit and continuing to plan during retirement can help to mitigate losses later in life.
Correspondence: Joanne Kaa Earl Department of Psychology, Macquarie University, Balaclava Road, North Ryde, Sydney, NSW 2109, Australia Email joanne.earl@mq.edu.au 
In addition to an absence of planning, there is also evidence of a disconnect between broader goals and later implementation. For example, a large proportion of those people that do plan (34\%) expect to exit the workforce by transitioning to part-time work yet the data suggest that people often exit more abruptly than anticipated and too early with insufficient funds. ${ }^{1}$ One of the possible explanations for this is a lack of goal specificity, an essential ingredient for implementation intention and goal commitment. ${ }^{4}$ According to Gollwitzer, ${ }^{5}$ an implementation intention is a specific plan indicating when, where, and how individuals will carry out the intended action. By formulating an implementation intention, one's mental representation of a specified situation can be activated and consequently the goal-directed action, when the situation is encountered, is efficient and conscious intent is not required; in other words, the action is automated. ${ }^{6}$ It was proposed by Tubbs and Ekeberg ${ }^{7}$ that goals and strategies may mutually influence each other because planning is useful for generating strategies under novel conditions and goal commitment may be influenced by engagement in planning.

In order to enhance the likelihood of successful goal attainment, effective planning and enactment of goal-oriented behaviors during the goal-striving phase are important. ${ }^{8}$ The benefits of forming an implementation intention are empirically supported in laboratory settings. ${ }^{910}$ Furthermore, the benefits of implementation intention on self-regulating behavior have been demonstrated in promoting health behaviors including cervical cancer screening and repeated daily behaviors such as vitamin supplement use, ${ }^{9}$ reducing unhealthy snacking habits, ${ }^{11}$ managing diet, ${ }^{12}$ and exercise. ${ }^{13}$ The design of a retirement intention promoting implementation intention is yet to be tested in the retirement context. While many factors have been found to predict planning in retirement, ${ }^{14-18}$ a lesser explored areas have been time perspective (TP). TP refers to the importance a person places on the past, the present, or the future. ${ }^{19} \mathrm{TP}$ has been linked to retirement planning ${ }^{20,21}$ as well as retirement outcomes such as adjustment ${ }^{20}$ and therefore worthy of further consideration. Despite the numerous studies identifying factors predicting retirement planning and adjustment, there are very few researched interventions and no online interventions. The current study reports on the design and evaluation of an evidencebased online intervention using TP as a theoretical framework for the improvement of retirement planning behaviors.

\section{Using time perspective as a theoretical framework}

The relationship between age and TP, particularly future TP, has been well documented. While earlier research emphasized the importance of the relationship between age and $\mathrm{TP},{ }^{22}$ more recent research suggests that the relationship between age and TP is less important than originally thought. ${ }^{23-25}$ Other recent longitudinal evidence suggests that TP is stable over time within individuals ${ }^{15}$ operating more like a personality variable and that a single TP may dominate behavior throughout the life span. ${ }^{26}$

Zimbardo and Boyd's TP theory ${ }^{19}$ was employed as the relevant model for this study. According to the model, there are five different domains of TP displayed by individuals. A Present-Fatalistic TP is more likely to result in leaving things to chance, assuming that events are the result of fate. Participants with high Future-Focused TP often give up enjoyment of the present to focus on future rewards and goals. High scores on the Present-Hedonistic scale are associated with instant gratification at the expense of long-term goals. Participants with high Past-Negative or Past-Positive TP focus primarily on either negative or positive associations with the past.

The intervention uses number and specificity of goals as outcomes and incorporates previous evidence that 1) TP is linked to retirement planning, 2) TP is stable over time, and 3) TP acts more like a trait than a state. The design assumes TP to be relatively stable and emphasis is placed on understanding it and then applying it to retirement planning behavior.

\section{Maximizing distribution and remote access}

The Internet provides enormous opportunities to distribute information and engage in online learning. Developing online learning interventions has the potential to help people when they need it most, regardless of their location. ${ }^{27}$ Stereotypes about older people and access to technology may prevent researchers from exploring this mode of delivery but in Australia, $83 \%$ of people aged 55-64 years were regular Internet users and the total number of households with Internet access continues to increase from $60 \%$ in 2005 to $>85 \% 10$ years later. ${ }^{28} \mathrm{We}$ opted for an online intervention with an eye to the future for Australian workers. A review by du Plessis et $\mathrm{al}^{27}$ provided numerous insights to inform the training design for older learners. Some of their recommendations incorporated into the design included providing learners with one module to complete each week allowing self-determining the pace of learning, optimizing a time free of distractions; providing individualized feedback on TP that was incorporated into their training, and enabling use of familiar technology so they could make adjustments customized to their needs (eg, increased screen size).

\section{Measuring intervention success: outcomes}

Goals act as a motivational source in retirement because they help the individual visualize their future wants and needs. ${ }^{3}$ 
Setting goals is considered a fundamental precursor to planning for retirement ${ }^{21}$ and consequently retirement well-being. In creating a detailed strategy to attain goals, there is a higher likelihood of goal success. To determine the efficacy of an individual's current goal setting, there are two measures of interest - the number of goals and the specificity of goals. Clarity of retirement goals is significantly associated with retirement planning behaviours ${ }^{29}$ and thus if one begins to set clear goals then he or she is more likely to plan pre- and postretirement.

Participants in the current study were educated on evidence-based goal-setting techniques and were required to list goals under five subheadings derived from the Dynamic Resource Model of Retirement. ${ }^{18}$ These different subheadings were commensurate with the Retirement Resources Inventory, ${ }^{16}$ including "wealth"-related goals, "health"-related goals, and "social"-related goals, goals on keeping "cognitively active", and goals on keeping "emotionally well". While planning for retirement has been shown to facilitate improved satisfaction, ${ }^{30}$ there is also evidence to suggest that an underpinning mechanism driving this relationship could be an individual's sense of environmental mastery. ${ }^{3}$
Incorporating elements of Kirkpatrick's training evaluation model, ${ }^{31}$ we also sought to understand whether participants learned about TP during the intervention and whether they gained insight into their and others behavior. Kirkpatrick's model ${ }^{31}$ emphasizes evaluation across four levels: reaction (did people enjoy the training?), learning (did they gain knowledge?), behavior (did they change their behavior?), and results (did training produce the final results or outcomes expected?). It was hypothesized that the intervention would increase participants' number and specificity of goals (behavior) and help them to better understand TP and how it related to them (learning) while enjoying the experience (reaction). It was beyond the scope of this study to determine whether goals were implemented (results).

\section{Patients and Methods Study design}

The present study is a mixed between-within design, using a combination of qualitative and quantitative measures, to examine the influence of an online training intervention on planning behavior for retirement (Figure 1). Ethics approval

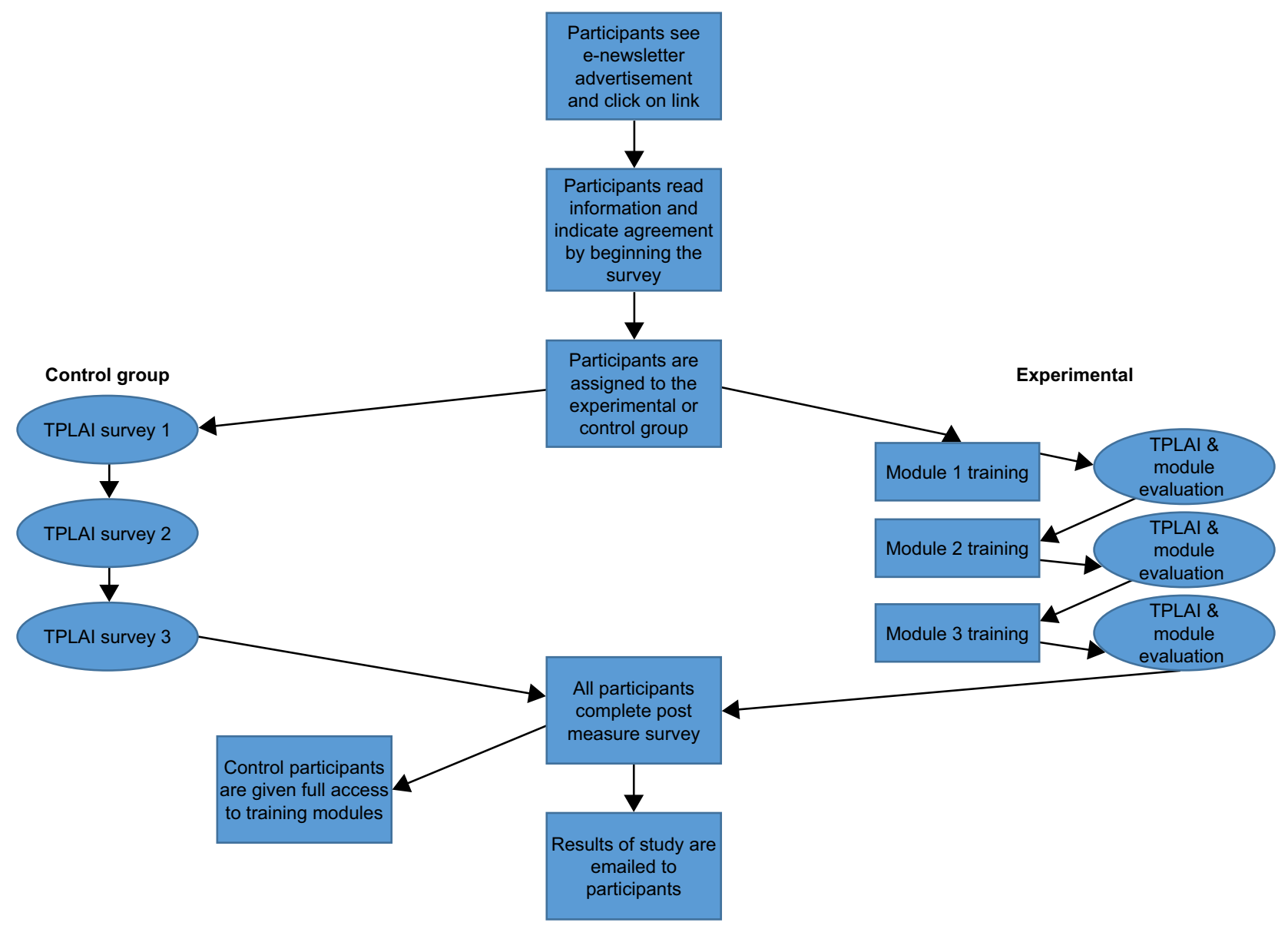

Figure I The design and sequence of the current study.

Abbreviation: TPLAl, time perspective learning and insight. 
for the study was provided by the University Human Research Ethics Advisory Panel (Psychology). Before beginning, the study participants read an information statement and indicated their agreement to participate by clicking on the link provided. The ethics consent included participant selection and purpose of the study, a description of the study and any associated risks, confidentiality, and disclosure of information. Participants were free not to participate or withdraw from the study at any time without prejudice.

\section{Participants}

The total sample contained 40 participants, 15 (37.5\%) male and $25(62.5 \%)$ female, ranging between 45 and 77 years of age $(M=58.17)$. In line with earlier findings that pre- and postplanning are equally important people who were working, fully retired and partially retired participants were all eligible for participation. The 40 participants were assigned to either the experimental $n=22$ (10 male) or control condition $\mathrm{n}=18$ (5 male). The control group was essentially waitlisted receiving only the same pre- and posttests as the experimental group. Details are shown in Figure 1. Within each condition, 14 participants identified themselves as still working with the remainder nominated as retired.

Please contact the corresponding author for supplemental materials and detailed examples of training materials.

\section{Training modules}

Examples of the training materials used can be accessed here: https://www.researchgate.net/project/Time-Perspectivebased-interventions-to-improve-retirement-planning.

A more detailed description of each module appears below.

\section{Training module I}

This module outlined the purpose of training and emphasized the importance of planning, its link to retirement outcomes as well as differences in expectations of retirees vs reality. For examples, many people believe they will live off their investments in retirement although a majority will need a state-provided pension. As part of the first module, experimental participants were provided with a Feedback Report detailing their most dominant TP and their results on the Retirement Resources Inventory. The modules were designed to be equally applicable to people pre- and postretirement. For preretirees, the message was to try accumulate resources before they leave work while the message for retirees was to normalize behavior and encourage people to keep planning.

\section{Training module 2}

The main objective of module 2 was to improve participants understanding of TP and have them identify how it may influence their propensity to plan for retirement. There were three main parts to this module: 1) understanding TP theory, 2) considering their retirement resource accumulation to date, and 3 ) the link between TP and their planning behavior.

\section{Training module 3}

The main objective of the third module was to integrate all the information learnt from previous modules (such as the importance of resource accumulation and understanding the theory of TP) in order to encourage new goal-setting behaviors. Reference was made to the SMART model ${ }^{32}$ emphasizing the need for goals to be Specific, Measureable, Attainable, Realistic, and Timely.

\section{Measures}

\section{Retirement planning and certainty}

Participants responded to a number of questions to better determine their retirement status and future plans. They were asked: "Are you fully retired?" (select one) and responded "No" or "Yes"; "What age do/did you expect to retire?" (open ended); and "How certain are/were you that you will retire at this age?" (answered with 0-100\%).

\section{Time perspective}

Zimbardo Time Perspective Inventory (ZTPI) ${ }^{19}$ is a selfreport 56-item measure that is used to identify an individual's TP. The ZPTI has five individual subscales: Past-Positive (0.80), Past-Negative (0.82), Present-Hedonistic (0.79), Present-Fatalistic (0.74), and Future-Focused (0.77). The reliabilities as reported by the original authors are reported in parentheses; due to sample sizes, reliability coefficients were not reported in this study.

\section{Number and specificity of goals set}

The methodology used by Petkoska and Earl ${ }^{21}$ was applied to measure the number and specificity of current goals. Participants listed their retirement goals under five resource categories, namely wealth, health, social, cognition, and emotional. For each participant, two scores (number of goals and specificity of goals) were calculated under each goal category.

Goal specificity was analyzed using a Grounded Theory approach to qualitative data analysis. ${ }^{33,34}$ Participants were invited to prepare goal statements. The statements were rated by two separate raters in relation to goal specificity. 
The scores of the two raters were compared to crossvalidate results. Goals that included no specific component, for instance, "exercise more", were scored a 0 . Goals that included four specific components, for instance, "tomorrow at 3 pm (1) I will contact a trainer (2) to help me exercise twice a week (3) so I can run five kilometers (4)" were scored a 4 . When ratings of the two raters were compared, and there was a difference of 1.5 points or more (ie, where they failed to reach agreement), these items were rejected from analysis. Scores of both raters ranged from 0 to 4 .

\section{Time perspective learning and insight}

There were two subscales within this measure: a learning component and an insight scale. The learning component focused on testing how much the participants had learned about TP. A typical item included: "For people with high scores on Past Negative, their childhood sights, sounds, and even smells often bring back a flood of wonderful memories" (negatively scored). There were five such items, scored as either True or False resulting in a total score out of 5 . The five insight items focused on the extent to which participants had applied TP in analyzing their own behavior or the behavior of others. A typical item included was "I can recognize how people around me differ in their Time Perspectives". These items were scored on a 5-point scale from very false (1) to very true (5). Scores were added and averaged to provide an overall score out of 5 .

\section{Results}

\section{Preliminary analysis}

The mean age of participants in the sample was 58.18 $(\mathrm{SD}=8.2)$ years and the mean expected age of retirement for those not yet retired was 63.10 years $(\mathrm{SD}=4.8)$. Furthermore, participant's certainty of retirement age for the unretired portion sample was $71.49 \%$. This indicated that, on average, participants were mostly sure they would retire at their anticipated age.

\section{Improvements in number of goals}

Table 1 represents the mean and SDs for the number of goals set by participants in each condition, across time. Results indicate that the intervention had an effect on the number of goals set by participants relating to "health" and "emotions".

It should be noted that for health-related goals (ie, lose 5 kilos before Christmas), experimental participants, on average, increased in the number of goals from time 1 to time 2 . The control participants, on average, decreased in their number of goals set between time 1 and time 2. Such findings were
Table I Mean and SD scores for number of goals by condition and across time

\begin{tabular}{|c|c|c|c|c|}
\hline \multirow[t]{2}{*}{ Measure } & \multicolumn{2}{|c|}{ Experimental } & \multicolumn{2}{|l|}{ Control } \\
\hline & Time I & Time 2 & ime I & Time 2 \\
\hline \multicolumn{5}{|l|}{ Number } \\
\hline Health (SD) & $2.15(1.35)$ & $3.35(1.18)^{* *}$ & $2.77(1.30)$ & $2.47(1.23)$ \\
\hline Wealt & $1.65(1.05)$ & $2.10(1.07)$ & $\mathrm{I} .4 \mathrm{I}(0.80)$ & $1.47(1.13)$ \\
\hline Social & $1.60(1.05)$ & $2.20(1.07)$ & $1.65(1.00)$ & $2.12(1.54)$ \\
\hline Cogni & $2.10(1.68)$ & $2.65(1.13)$ & $1.88(1.27)$ & $1.59(1.58)$ \\
\hline Emotio & $1.50(1.00)$ & 2.40 (I.64)* & $1.71(1.16)$ & $\mathrm{I} .53(\mathrm{I} .5 \mathrm{I})$ \\
\hline \multicolumn{5}{|l|}{ Specificity } \\
\hline Health ( & $1.61(0.58)$ & $2.84(0.78)^{* *}$ & $1.50(0.59)$ & $1.69(0.62)$ \\
\hline Wea & $1.66(0.7 \mathrm{I})$ & $2.59(0.87)$ & $1.42(0.67)$ & $1.72(0.73)$ \\
\hline Social (SD) & $1.46(0.55)$ & $2.14(0.73)$ & I. 14 (0.59) & $1.28(0.93)$ \\
\hline Cognitive (SD) & $1.30(0.78)$ & $2.25(0.80) * *$ & $1.33(0.84)$ & $1.17(0.66)$ \\
\hline Emotions (SD) & $1.18(0.65)$ & $1.68(0.75)^{* *}$ & $1.28(0.67)$ & $1.03(0.63)$ \\
\hline
\end{tabular}

Notes: All statistics in this table are accurate to two decimal places. ${ }^{*} P<0.05$ level, $* * P<0.0$ l level.

supported by the statistically significant difference between time $1(M=2.15, \mathrm{SD}=1.35)$ and time $2(M=3.35, \mathrm{SD}=1.18)$ in the experimental condition for goals $(F(1,35)=10.15$, $P<0.01,95 \%$ CI $[0.28,2.77])$. These findings are supported by a significant interaction. Results show a greater increase in the experimental condition than the control on emotionrelated goals $(F(1,35)=5.16, P<0.05,95 \%$ CI $[-0.22,2.37])$.

\section{Improvements in specificity of goals}

The means and SD scores for participants by condition and across time for specificity of set goals can be found in Table 1 . Scores vary between conditions on each category of goals and across time. Participants in both conditions reported a specificity of around 1.5 on health-related goals at time 1. However, participants in the experimental condition considerably increased the specificity of their goals set at time 2 . This interaction was found to be statistically significant $(F(1,38)=15.78, P<0.01,95 \%$ CI $[0.33,1.74])$, an outcome that supports the inference that the training intervention worked to increase participants' specificity of health-related goals at time 2 .

These results indicate that there is a substantial difference between specificity of goals relating to the accumulation of cognitive resources set by participants in the experimental condition at time 2 . In Table 1 , it can be seen that the specificity of goals for both conditions is approximately the same at time 1; however, at time 2 , the experimental condition substantially increased in specificity of goals, as compared to the control that appears to remain steady. It was found that this interaction is significant $(F(1,38)=13.15, P<0.01$, $95 \%$ CI $[0.28,1.96])$. 
Significant improvements were also reported in emotionrelated goals. At time 1, the specificity of emotion-related goals is the same for both conditions, whereas at time 2, the experimental condition substantially increases in goal specificity. It appears that the specificity of emotion-related goals remains steady, even decreasing. This difference was statistically significant $(F(1,38)=7.39, P<0.01,95 \% \mathrm{CI}$ $[0.00,1.50])$.

\section{Changes in time perspective learning}

Participants in the experimental condition and control condition increased their TP learning when tested after module 2 in comparison to modules 1 and 3 . The experimental condition increased from 4.36 to 4.68 . However, from modules 2 to 3 , the means remain relatively steady. The Bonferroni contrast for this analysis was $F \mathrm{C}=F_{0.05 ; 1,38}=4.098$.

\section{Changes in time perspective insight}

The experimental condition had a statistically higher level of TP insight $-(F(1,38)=6.28, P<0.05,95 \%$ CI $[0.28,2.66])-$ than participants in the control condition averaging across modules.

\section{Module evaluation}

The mean and SD scores for these evaluations can be found in Table 2. Engagement in the training progressed over the course of the three modules. Examination of participant's open-ended feedback for all modules allows three themes of possible improvement to emerge: 1) restructuring the content to include more activities and exercises in module 1, 2) clarifying instructions about how to navigate the site, and 3) adjusting the design to be more age appropriate for the group (ie, more use of photos and less use of cartoons). Positive aspects of the training highlighted were 1) the use of embedded video footage where the researcher talked about TP, 2) the appeal of an interactive design, and 3) the opportunity to gain a new perspective on themselves and others (ie, strengths training). Overall, the feedback provided through evaluation is critical to the development of

Table 2 Mean and SD scores for module evaluation

\begin{tabular}{l|l|l|l|l|l|l}
\hline \multirow{2}{*}{ Evaluation } & \multicolumn{2}{l|}{ Module I } & \multicolumn{2}{l|}{ Module 2 } & \multicolumn{2}{l}{ Module 3 } \\
\cline { 2 - 7 } & $\mathbf{M}$ & SD & M & SD & M & SD \\
\hline Interesting & 2.50 & 0.74 & 2.73 & 0.63 & 2.73 & 0.83 \\
Educational & 2.45 & 0.86 & 2.68 & 0.72 & 2.64 & 0.85 \\
Informative & 2.27 & 0.63 & 2.59 & 0.80 & 2.68 & 0.84 \\
Worthwhile & 2.59 & 0.73 & 2.64 & 0.79 & 2.91 & 0.68 \\
\hline
\end{tabular}

Note: All statistics in this table are accurate to two decimal places. this research and should be incorporated into the design of future interventions.

\section{Discussion and conclusion}

The current study sought to expand the retirement literature in two ways: first, by designing and testing an evidence-based intervention for the improvement of retirement planning behavior using TP as a theoretical framework and second, to inform the development of future interventions by evaluating the training modules used in the study.

\section{Intervention effectiveness}

It was hypothesized that the intervention would increase participants' number and specificity of goals (in Hypotheses 1 and 2). The results indicated that participants assigned to the experimental condition showed an increase in the number and specificity of retirement goals (in areas relating to health, social needs, and emotional needs).

\section{Improvements in time perspective learning and insight}

Consistent with the hypothesis, there was evidence of learning from participation (in Hypothesis 3 ) as well as greater insight into their own and other's behavior (in Hypothesis 4).

\section{Limitations and future recommendations}

As discussed, the relatively short timeframe hindered the collection of data relating to resource accumulation. Given that existing research highlights the gradual acquisition of retirement resources,${ }^{18}$ it would be useful to measure these variables at a 6- to 12-month delay. It is also recommended that the researchers tease apart the different elements (ie, the use of feedback with and without training) incorporated into the comprehensive design. For example, a future research project could include a third condition entitled "feedback only", whereby participants do not receive the intervention but only the feedback report detailing dominant TPs. This condition would allow inferences to be made regarding the singular impact of the feedback on participants' planning behaviors.

\section{Disclosure}

The authors report no conflicts of interest in this work.

\section{References}

1. Australian Bureau of Statistics [webpage on the Internet]. Retirement and retirement intentions Australia, 2016 to June 2017 (Release Number 6238); 2018. Available from: http://www.abs.gov.au/ausstats/abs@.nsf/ mf/6238.0. Accessed November 26, 2018. 
2. Donaldson T, Earl JK, Muratore AM. Extending the integrated model of retirement adjustment: incorporating mastery and retirement planning. J Vocat Behav. 2010;77(2):279-289.

3. Topa G, Moriano JA, Depolo M, Alcover CM, Morales JF. Antecedents and consequences of retirement planning and decision-making: a meta-analysis and model. J Vocat Behav. 2009;75(1):38-55.

4. Diefendorff JM, Lord RG. The volitional and strategic effects of planning on task performance and goal commitment. Hum Perform. 2003; 16(4):365-387.

5. Gollwitzer PM. Goal achievement: the role of intentions. Eur Rev Soc Psychol. 1993;4(1):141-185.

6. Bargh JA, Chen M, Burrows L. Automaticity of social behavior: direct effects of trait construct and stereotype activation on action. J Pers Soc Psychol. 1996;71(2):230-244.

7. Tubbs ME, Ekeberg SE. The role of intentions in work motivation: implications for goal-setting theory and research. Acad Manage Rev. 1991;16(1):180-199.

8. Gollwitzer PM. Implementation intentions: strong effects of simple plans. Am Psychol. 1999;54(7):493-503.

9. Ajzen I, Czasch C, Flood MG. From intentions to behavior: implementation intention, commitment, and conscientiousness. J Appl Soc Psychol. 2009;39(6):1356-1372.

10. Brandstätter V, Lengfelder A, Gollwitzer PM. Implementation intentions and efficient action initiation. J Pers Soc Psychol. 2001;81(5):946-960.

11. Tam L, Bagozzi RP, Spanjol J. When planning is not enough: the selfregulatory effect of implementation intentions on changing snacking habits. Health Psychol. 2010;29(3):284-292.

12. Adriaanse MA, Vinkers CD, De Ridder DT, Hox JJ, De Wit JB. Do implementation intentions help to eat a healthy diet? A systematic review and meta-analysis of the empirical evidence. Appetite. 2011;56(1):183-193.

13. Bélanger-Gravel A, Godin G, Amireault S. A meta-analytic review of the effect of implementation intentions on physical activity. Health Psychol Rev. 2013;7(1):23-54.

14. Agnew J, Bateman H, Thorp S. Financial literacy and retirement planning in Australia. Numeracy. 2013;6(2):1-25.

15. Earl JK, Archibald H. Retirement planning is more than just accumulating resources. Eur J Manag. 2014;14:21-36.

16. Leung CSY, Earl JK. Retirement resources inventory: construction, factor structure and psychometric properties. J Vocat Behav. 2012 81(2):171-182.

17. Lusardi A, Mitchell OS. The economic importance of financial literacy: theory and evidence. J Econ Lit. 2014;52(1):5-44.

18. Wang M. Profiling retirees in the retirement transition and adjustment process: examining the longitudinal change patterns of retirees' psychological well-being. J Appl Psychol. 2007;92(2):455-474.
19. Zimbardo PG, Boyd JN. Putting time in perspective: a valid, reliable individual-differences metric. J Pers Soc Psychol. 1999;77(6): 1271-1288.

20. Earl JK, Bednall TC, Muratore AM. A matter of time: why some people plan for retirement and others do not. Work Aging Retire. 2015;1(2): 181-189.

21. Petkoska J, Earl JK. Understanding the influence of demographic and psychological variables on retirement planning. Psychol Aging. 2009; 24(1):245-251.

22. Kooij D, Bal PM, Kanfer R. Future time perspective and promotion focus as determinants of intraindividual change in work motivation. Psychol Aging. 2014;29(2):319-328.

23. Bohn L, Kwong See ST, Fung HH. Time perspective and positivity effects in Alzheimer's disease. Psychol Aging. 2016;31(6):574-582.

24. Grühn D, Sharifian N, Chu Q. The limits of a limited future time perspective in explaining age differences in emotional functioning. Psychol Aging. 2016;31(6):583-593.

25. Tasdemir-Ozdes A, Strickland-Hughes CM, Bluck S, Ebner NC. Future perspective and healthy lifestyle choices in adulthood. Psychol Aging. 2016;31(6):618-630.

26. Gupta R, Hershey DA, Gaur J. Time perspective and procrastination in the workplace: an empirical investigation. Curr Psychol. 2012;31(2): 195-211.

27. du Plessis K, Anstey KJ, Schlumppa A. Older adults' training courses: considerations for course design and the development of learning materials. Aust J Adult Learn. 2011;51:161-174.

28. Australian Bureau of Statistics [webpage on the Internet]. Household use of information technology, Australia, 2016-17 (Release Number 8146.0). Available from: http://www.abs.gov.au/AUSSTATS/abs@. nsf/DetailsPage/8146.02016-17?OpenDocument. Accessed November $26,2018$.

29. Stawski RS, Hershey DA, Jacobs-Lawson JM. Goal clarity and financial planning activities as determinants of retirement savings contributions Int J Aging Hum Dev. 2007;64(1):13-32.

30. Bateman H, Deetlefs J, Dobrescu LI, Newell BR, Ortmann A, Thorp S Just Interested or getting involved? An analysis of superannuation attitudes and actions. Econ Rec. 2014;90(289):160-178.

31. Kirkpatrick DL. Evaluating Training Programs: The Four Levels. San Francisco: Berrett-Koehler; 1994

32. Bachiochi PD, Weiner SP. Qualitative data collection and analysis. In: Rogelberg SG, editor. Handbook of Research Methods in Industrial and Organizational Psychology. Oxford: Blackwell; 2004:161-183.

33. Conzemius A, O’Neill J. The Power of Smart Goals: Using Goals to Improve Student Learning. Indiana: Solution Tree Press; 2005.

34. Charmaz K. Grounded theory. Qual Psychol. 2003;1:81-110.
Clinical Interventions in Aging

\section{Publish your work in this journal}

Clinical Interventions in Aging is an international, peer-reviewed journal focusing on evidence-based reports on the value or lack thereof of treatments intended to prevent or delay the onset of maladaptive correlates of aging in human beings. This journal is indexed on PubMed Central, MedLine,

\section{Dovepress}

CAS, Scopus and the Elsevier Bibliographic databases. The manuscript management system is completely online and includes a very quick and fair peer-review system, which is all easy to use. Visit http://www.dovepress. com/testimonials.php to read real quotes from published authors. 